\title{
VALIDAÇÃO DE INSTRUMENTO SOBRE ENGAJAMENTO E DESENGAJAMENTO MORAL DE DOCENTES DIANTE DO BULLYING NA ESCOLA
}

\author{
VALIDACIÓN DE INSTRUMENTO SOBRE COMPROMISO Y DESCOMPROMISO \\ MORAL DE DOCENTES ANTE EL BULLYING EN LA ESCUELA
}

\author{
VALIDATION OF INSTRUMENT ON MORAL ENGAGEMENT AND \\ DISENGAGEMENT OF TEACHERS IN THE FACE OF BULLYING AT SCHOOL
}

\author{
Luciene Regina Paulino TOGNETTA ${ }^{1}$ \\ José Maria Avilés MARTÍNEZ ${ }^{2}$ \\ Catarina Carneiro GONÇALVES ${ }^{3}$ \\ Fernando ANDRADE ${ }^{4}$ \\ Larissa Di Genova BONI ${ }^{5}$ \\ Natália Cristina Pupin SANTOS ${ }^{6}$
}

RESUMO: Embora o bullying ocorra nas relações paritárias, sua prevenção e superação na escola demandam intervenção de docentes, que precisam ser capazes de levar estudantes à consciência do conteúdo moral em jogo numa situação de vitimização: isso requer dos professores conhecimento sobre valores implicados nesta violência, sensibilizando-se diante dela. Todavia, estudos evidenciam que muitos professores responsabilizam os alvos pelas situações de maus tratos ou deslocam a responsabilidade de intervir para as famílias: para tanto, valem-se de desengajamentos morais através dos quais diminuem ou refutam o problema, impossibilitando ações para superá-lo. Assim, objetivamos validar instrumento de pesquisa capaz de identificar as formas mais recorrentes de Desengajamento ou Engajamento Moral manifestas por docentes. Após ampla revisão da literatura, elaboraram-se duas histórias caracterizando situações envolvendo alvo típico e provocador, seguidas de 14 itens avaliativos adequados às oito formas de Desengajamento Moral definidas por Bandura e três formas de Engajamento Moral construídas para esta pesquisa. Após a Análise de Componentes

${ }^{1}$ Universidade Estadual Paulista (UNESP), Araraquara - SP - Brasil. Professora no Departamento de Psicologia da Educação da Faculdade de Ciências e Letras e Líder do GEPEM - Grupo de Estudos e Pesquisas em Educação Moral (UNESP/UNICAMP). Doutorado em Psicologia Escolar e do Desenvolvimento Humano (USP). ORCID: https://orcid.org/0000-0003-0929-4925. E-mail: lrpaulino@uol.com.br

2 Universidad de Valladolid (UVA), Valladolid - Espanha. Professor no Departamento de Psicologia da Faculdade de Educação e Serviço Social. Área de Personalidade, Avaliação e Tratamento Psicológico. ORCID: https://orcid.org/0000-0001-9179-6427. E-mail: aviles@uva.es

${ }^{3}$ Universidade Federal da Paraíba (UFPB), João Pessoa - PB - Brasil. Professora Adjunta no Departamento de Habilitações Pedagógicas. Doutorado em Educação (UFPB). ORCID: https://orcid.org/0000-0003-2508-2762. Email: catarinacgon@hotmail.com

${ }^{4}$ Universidade Federal da Paraíba (UFPB), João Pessoa - PB - Brasil. Professor Associado no Departamento de Fundamentação da Educação e dos Programas de Pós-graduação em Educação e em Direitos Humanos, Cidadania e Políticas Públicas. Doutorado em Educação (UFPB). ORCID: https://orcid.org/0000-0003-05542514. E-mail: frazec66@gmail.com

${ }^{5}$ Universidade Estadual Paulista (UNESP), Araraquara - SP - Brasil. Mestranda no Programa de Pós-graduação em Educação Escolar. ORCID: https://orcid.org/0000-0003-0796-9124. E-mail: ldgenova@hotmail.com

${ }^{6}$ Universidade Estadual Paulista (UNESP), Araraquara - SP - Brasil. Mestranda no Programa de Pós-graduação em Educação Escolar. Membro do GEPEM - Grupo de Estudos e Pesquisas em Educação Moral (UNESP/UNICAMP). ORCID: https://orcid.org/0000-0001-9847-632X. E-mail: nati.cps30@hotmail.com

RIAEE - Revista Ibero-Americana de Estudos em Educação, Araraquara, v. 16, n. 1, p. 292-319, jan./mar. 2021. e-ISSN: 1982-5587 DOI: https://doi.org/10.21723/riaee.v16i1.14477 
Principais, aplicou-se o instrumento a uma amostra de 921 professores de escolas brasileiras e espanholas. Os resultados demonstraram a aceitação do modelo teórico proposto, cargas fatoriais significantes nos diferentes fatores e adequada fidedignidade do instrumento.

PALAVRAS-CHAVE: Validação de instrumento. Engajamentos e desengajamentos morais. Docentes. Bullying.

RESUMEN: Aunque el bullying se pase en las relaciones entre iguales, su prevención y superación en la escuela demandan intervención de los docentes, que necesitan lograr llevar los estudiantes a la consciencia del contenido moral en juego en una situación de victimización: lo que requiere de los profesores conocimientos sobre valores implicados en esta violencia, sensibilizándose frente a ella. Sin embargo, estudios aclaran que muchos profesores responsabilizan las victimas por las situaciones de malos tratos o quitan su responsabilidad de intervenir, pasándola a las familias: para ello, se valen de descompromisos morales a través de los cuales disminuyen o rechazan el problema, imposibilitando acciones para superarlo. Así, objetivamos validar el instrumento de investigación capaz de identificar las formas más recurrentes de descompromiso o compromiso moral manifiestas por docentes. Tras amplia revisión de la literatura, se elaboró dos historias caracterizando situaciones involucrando objeto típico y provocador, seguidas de 14 items evaluativos adecuados a las ocho formas de desconexión moral definidas por Bandura y tres formas de conexión moral construidas para esta investigación. Tras el Análisis de Componentes Principales, se aplicó el instrumento a una muestra de 921 profesores de escuelas brasileñas y españolas. Los resultados demuestran la aceptación del modelo teórico propuesto, cargas factoriales significantes en los distintos factores y adecuada fiabilidad del instrumento.

PALABRAS CLAVE: Validación de instrumento. Conexión y desconexión morales. Docentes. Bullying.

ABSTRACT: Although bullying occurs in parental relationships, its prevention and overcoming in school demand the intervention of teachers, who need to be able to bring students to the awareness of the moral content at stake in a situation of victimization: this requires teachers to know about values involved in this violence, sensitizing themselves to it. However, studies show that many teachers blame targets for situations of mistreatment or displace the responsibility of intervention for families: they use moral disengagement through which they reduce or refute the problem, making it impossible to overcome it. Thus, we aim to validate a research instrument capable of identifying the most recurrent forms of Disengagement or Moral Engagement manifested by teachers. After extensive review of the literature, two stories were developed characterizing situations involving typical and provocative target, followed by 14 evaluative items appropriate to the eight forms of Moral Disengagement defined by Bandura and three forms of Moral Engagement constructed for this research. After the Principal Components Analysis, the instrument was applied to a sample of 921 teachers from Brazilian and Spanish schools. The results demonstrated the acceptance of the proposed theoretical model, significant factorial loads in the different factors and adequate trustworthiness of the instrument.

KEYWORDS: Validation of Instrument. Moral engagement and disengagements. Teacher. Bullying. 


\section{Introdução}

[...] certa vez no colégio pegaram Wellington de cabeça para baixo, botaram dentro da privada e deram descarga. Algumas pessoas instigavam as meninas: "vai lá, mexe com ele". Ou até incentivo delas mesmo: "Vamos brincar com ele, vamos sacanear". As meninas passavam a mão nele [...]. (Fantástico, 2011).

A epígrafe a este artigo é extrato de depoimento dado a um programa televisivo brasileiro a respeito de Wellington da Silveira, jovem de 23 anos que adentrou uma escola do Rio de Janeiro atirando contra estudantes e docentes, numa chacina que chocou o país, considerada a mais grave em escola brasileira, cometida por um ex-aluno. Além de trágico, por culminar com doze mortos - dentre os quais o próprio atirador - e treze feridos, o Massacre de Realengo (nome pelo qual ficou conhecido o episódio) ampliou a discussão em torno das questões que envolvem a convivência na escola, fazendo-se um alerta sobre as implicações que as práticas de bullying podem trazer para o desenvolvimento de crianças e adolescentes.

Se nenhum evento dessa natureza pode ser explicado de forma pontual, isolada ou linear, é preciso questionar o fato de Wellington da Silveira matar justamente na escola em que estudara dez anos antes e que, por inúmeros relatos como o da epígrafe, foi, para ele, palco de maus tratos sistemáticos perpetrados pelos seus pares, sobretudo pelas meninas principais alvos de sua chacina. Longe de ser um caso isolado, essa história vê-se repetida em muitos aspectos, em inúmeros outros episódios de violência extrema no Brasil e no mundo, evidenciando-se uma relação estreita entre as ações dos agressores e suas experiências em âmbito educacional.

Foi preciso mais um massacre recente em uma escola pública paulista, do município de Suzano - a Escola Raul Brasil - para que se tornasse ainda mais urgente a discussão sobre a complexidade da natureza do bullying. Com um prejuízo de 10 mortos, entre professores, funcionários e alunos, a escola Raul Brasil segue depois da tragédia - ocorrida em abril de 2019 - vivendo seu luto, sua dor e o medo de que dias de horror possam se repetir.

Fatos que se repetem e se caracterizam pela violência tomada como um valor para aqueles que matam. Além de sua incidência, a literatura brasileira já tem mostrado a complexidade de um fenômeno que afeta cada vez mais escolas, não como um problema de convivência cuja frequência é maior do que as indisciplinas, mas exatamente por sua crueldade (AVILÉS, 2006; 2015; FISCHER, 2010; FRICK, 2011; 2016; GONCALVES, 
2011; MASCARENHAS, 2006; 2009; OLWEUS, 1993; SANCHÉZ et al., 2012; TOGNETTA; VINHA, 2008; 2010; TOGNETTA; ROSÁRIO, 2013).

Ora, não obstante o conhecimento já produzido, as situações de bullying ainda são compreendidas de forma muito estereotipada pelos profissionais da educação, de modo que nas escolas persiste uma ampla crença de que o bullying somente imita uma sociedade na qual a violência e as perturbações à ordem lhes são comuns (GONÇALVES, 2011; 2017). Diante da alta incidência de bullying na escola (FISCHER, 2010), professores buscam explicar esta violência a partir da crença de que ela deriva, exclusivamente, de falhas na educação parental: foram os pais que não souberam dar limites ou, ainda, não foram firmes o suficiente (GONÇALVES, 2017; RIBEIRO; GONÇALVES; SANTOS, 2018). Com isso, terminam por omitir-se diante deste problema, deixando discentes - alvos, autores e espectadores de bullying - entregues à própria sorte.

Com efeito, há pouca ou nenhuma intervenção docente no enfrentamento dos maus tratos vividos pelos estudantes, como evidencia Fischer (2010). Logo, o bullying é negado, mal interpretado ou manejado com intervenções ineficazes e passageiras que ressaltam, ainda, o despreparo do professorado brasileiro para prevenir e intervir em problemas de convivência dos quais o bullying é, talvez, o pior. Isso porque o bullying é um problema entre pares, e, portanto, entendido pela Psicologia Moral como demasiado grave, ao atingir a construção da identidade - o outro é, para mim, aquele que me serve de espelho para refletir a minha própria imagem na construção identitária (TOGNETTA; VINHA, 2008; TOGNETTA; ROSÁRIO, 2013).

Assim, considera-se urgente conhecer as formas como as práticas de bullying têm sido interpretadas e abordadas pelos professores nas escolas. Isso porque, como destacam Tognetta et al. (2013), costumeiramente as instituições educativas resolvem os conflitos entre alunos chamando as famílias para se queixarem dos comportamentos dos estudantes e/ou suspendendo alunos e alunas como forma de mostrar aos demais que comportamentos antissociais não ficarão impunes. As escolas acreditam, com isso, garantir ensinar a todos o que deve ou não ser feito, como se tudo se resumisse à imitação de papéis adequados. Esse cenário de omissão e indiferença daqueles que deveriam garantir a segurança e o respeito entre discentes impede a aprendizagem de formas mais humanizadas para a convivência com o outro e com as diferenças (DAUD, 2018; GONÇALVES, 2017), chegando a afetar, com um clima institucional aversivo, o desempenho escolar de vários discentes. 
Reconhecendo este cenário, indagamo-nos: quais são as justificativas evocadas por docentes para justificar a omissão diante das situações de bullying que envolvem os estudantes nas escolas? Desta questão delimitou-se o objetivo deste estudo: validar um instrumento de pesquisa construído para identificar as formas de Desengajamento e Engajamento Moral de professores diante do bullying na escola. Esta investigação pretende indicar a tendência notadamente humana de "engajar-se ou desengajar-se" moralmente diante de circunstâncias violentas. No auge de certa "crise moral" em que o mundo político tem se consumido, a temática escolhida nos aproxima de explicações sobre a dificuldade, na escola, em adotar a perspectiva alheia e comprometer-se com valores prósociais no ensino-aprendizagem para a convivência democrática e pacífica.

Tendo uma abordagem de pesquisa baseada em métodos mistos, este estudo, de natureza exploratória, busca conhecer o cenário intercruzado dos julgamentos docentes diante do bullying na escola, manifestos via Engajamento ou Desengajamento Moral. Sampieri et al. (2010) e Sampieri, Collado e Lucio (2013) indicam que um estudo se define como exploratório quando sua problemática tenha sido pouco ou nada explorada com o rigor científico necessário e, dessa forma, ainda suscite dúvidas acerca de sua composição. Portanto, pensamos que a escolha de tal tipo de pesquisa se apresenta coerente com a perspectiva da temática, por envolver o bullying como um problema moral, sobretudo correlacionado aos constructos Desengajamento e/ou Engajamento Moral e formação de professores.

\section{Os constructos em discussão}

\section{Bullying}

Os primeiros estudos sobre bullying são atribuídos ao médico alemão Peter-Paul Heinemann, que publicou na Suécia, em 1972, suas observações sobre algumas atitudes agressivas de pequenos grupos de crianças contra uma única criança fora da sala de aula (OLWEUS, 1999; RONALD, 2010). Heinemann denominou essas condutas infantis de möbbing, estabelecendo uma relação entre essas ações e o comportamento de alguns animais. Assim, para o autor, möbbing indica o ataque de um grupo de animais a outro animal considerado perigoso (GUIMARÃES; RIMOLI, 2006). Do ponto de vista da psicologia, o pesquisador atribuiu as causas dos ataques à ira e à aversão, que se tornaram efetivos através 
de ameaças e atos de humilhação ocorridos entre os sujeitos (BERKOWITZ, 1993; DODGE, 1991; DODGE; COIE, 1987; RONALD, 2010).

Interessado nas relações entre pares e nos conflitos manifestos nestas relações, o norueguês Dan Olweus ofereceu mais elementos para compreensão das relações entre pares, ao publicar, em 1978, um estudo no qual apontou que 5\% dos meninos suecos, vítimas de maus tratos ocorridos nas escolas, sofriam estas agressões graves de forma persistente. Através desta observação, Olweus (1978) questionou a expressão möbbing, fazendo adoção, pela primeira vez, do termo bullying para referir-se à intimidação sistemática. Este conceito, derivado do vocábulo bully, pode significar "intimidar" como verbo ou "valentão" como substantivo.

Para caracterizar e delimitar o bullying, Olweus definiu três critérios essenciais: (a) é um comportamento agressivo marcado pela intencionalidade em causar o dano; (b) que ocorre repetidamente e ao longo do tempo; (c) em um contexto das relações interpessoais caracterizadas por um desequilíbrio de poder. O autor acrescentou, ainda, que essas intimidações podem ocorrer sem que haja um motivo aparente (OLWEUS, 1978, 1981).

A década de 1970 se tornou um importante marco para a comunidade científica na descoberta deste problema, a partir do amadurecimento das definições e terminologias relativas ao bullying, favorecendo sua caracterização e delimitação. A partir da década de 1980 expandiram-se os estudos sobre bullying, a partir da repercussão dos primeiros diagnósticos realizados nos demais países da Escandinávia (LAGERSPETZ et al., 1982; OLWEUS; ROLAND 1983; ROLAND, 2010). Outros países europeus, além dos Estados Unidos, da Austrália e do Japão contribuíram com pesquisas no intuito de revelar as influências socioculturais, individuais, grupais, escolares e familiares em torno do fenômeno (AVILÉS, 2006; SÁNCHEZ; ORTEGA, 2010; AVILÉS, 2013).

No Brasil, segundo Nascimento (2009), encontramos os primeiros trabalhos debruçados na compreensão do bullying a partir dos estudos de Canfield e seus colaboradores. Estas pesquisas utilizaram, como trilhos metodológicos, os mesmos caminhos apontados por Olweus: aplicação de questionários para uma grande população de alunos, caracterização do fenômeno a partir da perspectiva do autor norueguês e foco na incidência das manifestações de bullying.

Os estudos iniciais em torno da delimitação do bullying permitiram uma melhor compreensão desta forma de violência à medida que diferenciaram esta prática de outras manifestações de violência escolar. A este respeito, Avilés (2013) chama atenção para o fato 
de que no bullying se manifestam verdadeiros atos de intimidação preconcebidos, ameaças, que, sistematicamente, com violência física e psicológica, são de modo recorrente impostos a indivíduos numa relação paritária entre os envolvidos. Del Barrio et al. (2005) também chamam atenção para outra particularidade do fenômeno. Nos casos de bullying nem sempre temos apenas a manifestação da violência perceptível. Há, não raro, outros exemplos de comportamento, tais como a exclusão social (o ostracismo), que, por não serem sempre vistos como formas de violência, dificultam a intervenção para sua superação.

A literatura tem evidenciado uma tendência por parte dos profissionais das escolas de justificarem os maus tratos vividos pelos estudantes e, com isso, encontrarem razões para se exonerarem da função de combater a violência (o que é representado por formas de desengajamento moral). Isso porque docentes julgam possuírem os alvos a responsabilidade pelos maus tratos vividos ou, ainda, que os autores praticam tais violências porque não foram devidamente educados em casa (GONÇALVES, 2011). Desengajando-se, isentam-se de intervir frente à superação do problema. Por isso, embora reconheçamos que a superação do bullying é mais eficaz quando liderada pelos próprios estudantes (Lapa, 2019), consideramos que a omissão docente diante do problema é bastante grave, pois sem a cultura do apoio entre pares difundida em nosso país resta, apenas, que os envolvidos na violência possam, com sorte, contar com seus professores para superar a vitimização sofrida.

\section{Desengajamentos morais}

O termo "Desengajamento Moral" foi usado pela primeira vez por Bandura (1999; 2002), para se referir às formas pelas quais as pessoas agem de maneira desapegada ao problema do outro sem que haja, por isso, culpa ou vergonha. Para o autor, são 8 as formas de desengajar-se moralmente: Deslocamento de Responsabilidade, Difusão de Responsabilidade, Comparação Vantajosa, Minimização ou Distorção das Consequências, Atribuição de Culpa, Desumanização, Linguagem Eufemística e Justificativa Moral.

Tais mecanismos tornam possível que o sujeito possa dar novo sentido a uma conduta moralmente reprovável até o ponto de torná-la moralmente justificável, permitindo que, através dela, ele possa, ao mesmo tempo, ser "humano" ou "cruel", bom ou mau, diante dos outros, dependendo, assim, de quem ele inclui ou exclui de sua "categoria de humanidade".

No caso de docentes diante do bullying, em situação ideal (de engajamento moral), os professores tomam o problema (de resto, indesejável) como excelente oportunidade para que 
alunos e alunas se desenvolvam moralmente, contribuindo, assim, para a construção de suas personalidades éticas e a superação da violência não apenas na escola, mas, sobretudo, fora dela. Ora, conforme a teoria piagetiana sobre o desenvolvimento moral (PIAGET, 1994; 2007), ao tomarem conflitos como oportunidade de aprendizagem de valores pró-sociais, docentes e adultos em geral aproveitam a convivência entre crianças e adolescentes para transformá-la por meio de ações de respeito mútuo e de responsabilização coletiva, sobrepondo-se à ordem autoritária e expiatória. Com esta configuração, as crianças e adolescentes estabelecem relações de confiança e reciprocidade que favorecem $o$ desenvolvimento moral, impossível, segundo Piaget, de ser conquistado em atmosfera de autoridade e opressão. É por isso que, para enfrentar o bullying e superar as diversas formas de violência, é necessário que educadores se impliquem diante do fenômeno, de modo a garantirem que a dignidade de todos seja preservada na escola.

Como demonstra Piaget (1994), sendo ainda heterônomas, as crianças não conseguem julgar objetivamente os adultos significativos, dada à ambivalência de seus sentimentos a respeito deles. Logo, as relações que estabelecemos com as figuras de autoridade "são suscetíveis de atuar durante toda a infância e de prevalecer sobre os demais de acordo com o tipo de educação moral adotada" (PIAGET, 2007, p. 66), o que acentua a importância docente.

Consequentemente, quando docentes se desengajam moralmente diante de situações de bullying, terminam por construir na escola uma cultura em que as ações violentas são possíveis ou, ainda, consideradas justas e/ou merecidas: por exemplo, é comum docentes considerarem o alvo como merecedor da violência e os demais alunos da escola fazerem o mesmo julgamento.

\section{A formação de professores}

Educar para a convivência comumente é visto por docentes como tarefa familiar, pelas causas da violência serem atribuídas às famílias. A este respeito, Lobato $(2006$, p. 7) resume bem a crença docente pela qual a violência é problema doméstico e, consequentemente, seu manejo é responsabilidade familiar: "foi a família quem perdeu o controle sobre o jovem, foram os pais que não cumpriram a sua obrigação de educar os filhos e jogaram o peso desta responsabilidade, exclusivamente, para a escola".

Nota-se, sobre isso, a necessidade de superação de julgamentos equivocados dos docentes diante das situações de bullying na escola, segundo os quais eles atribuem o RIAEE - Revista Ibero-Americana de Estudos em Educação, Araraquara, v. 16, n. 1, p. 292-319, jan./mar. 2021. e-ISSN: 1982-5587 
problema à falta de educação doméstica ou à desestrutura familiar, naturalizando a violência numa sociedade "desestruturada" como a atual. Esta compreensão sobre o fenômeno é bastante problemática, visto que "naturalizar a violência não explica bem as causas desse fenômeno e termina por acolher um pessimismo niilista que não favorece a pedagogia" (ANDRADE, 2007, p. 25).

A notória falta de conhecimentos dos profissionais da Educação sobre a natureza do fenômeno e suas consequências negativas contribui à sua alusão como brincadeiras inofensivas, posto que a maioria das agressões que são entendidas como bullying apresentam caráter discreto aos olhares dos professores (CRAIG; BELL; LESCHIED, 2011; SILVA, 2014).

Pesquisas apontam que a omissão dos professores é a postura mais comum diante dos episódios de bullying, tanto dos episódios percebidos pelas vias da observação quanto pelos relatos de seus alunos (SILVA, 2014; YOON et al., 2011). Sobre os depoimentos a respeito da intervenção frente ao bullying, apesar de $85 \%$ dos docentes afirmarem agir diante do problema, apenas 35\% dos estudantes confirmam a veracidade desta afirmação. Este dado discordante foi verificado em diversas pesquisas similares. (FISCHER, 2010; JAMES, 2010; RIGBY; BAGSHAW, 2003; EMBRACE CIVILITY, 2016).

Nessa direção, estudos evidenciam a urgente necessidade de intervenção escolar (DÍAZ-AGUADO, 2015; FISCHER, 2010; GONÇALVES, 2011; OLWEUS, 1993), pautada no princípio de que a escola, por ser lócus privilegiado de convivência com a diferença e de formação moral, deve se responsabilizar por formar estudantes mais autônomos, capazes de conseguir respeitar a dignidade dos outros, ao se sentirem respeitados.

$\mathrm{Na}$ contramão dessa necessidade, as políticas de enfrentamento do bullying estão percorrendo outros caminhos, promulgando leis que pouco favorecem a superação do problema e não levam docentes a engajarem-se diante das situações nas quais o bullying se manifesta, terceirizando sua a resolução e, com isso, favorecem práticas de Desengajamento Moral.

Por isso, é importante que a formação de educadores seja prioridade e que temas ligados ao enfrentamento das violências, incluindo o bullying, estejam na pauta da formação inicial e continuada de educadores. Não há dúvidas de que os educadores e educadoras precisam assumir a tarefa de enfrentar a violência e formar moralmente os educandos. Mas como dar conta dessa demanda enquanto docentes são formados em cursos de graduação sem que tenham boas oportunidades de construir competências acerca do trabalho com ética e 
moral na escola? Conforme aponta Tognetta (2009, p. 13), "basta olhar para o currículo dos cursos formadores de professores para constatar que [...] em praticamente nenhuma ementa se pode encontrar educação moral, ou formação ética, como se deseje chamar”.

Tal ausência se expressa tanto no desconhecimento da necessidade desse trabalho interventivo quanto no uso de ações ineficazes de enfrentamento da violência. Isso porque, em matéria de ética, só pode ensinar quem a possui. Essa convicção é provavelmente fator que mantém ainda pequeno o número de projetos escolares com foco na gestão do bullying na escola. Ações nesse sentido são pontuais e direcionadas especificamente aos autores, centrando-se em advertências, expulsões, suspensões e convocação dos familiares para conversa (FISCHER, 2010), ignorando, completamente, a existência dos espectadores e a função de manutenção da violência que eles assumem.

\section{A presente pesquisa: A construção e validação de um instrumento de engajamento e desengajamento moral}

Esta pesquisa é necessariamente o fio condutor para realização de outras pesquisas cujo cerne estejam na formação de professores e superação do bullying. Certamente, inspirados em Jean Piaget, lembramo-nos de que é preciso alcançar o máximo de conhecimento sobre um novo fenômeno para que se possa orientar ações a seu respeito.

\section{Objetivo}

Validar um instrumento que indicasse os mecanismos de engajamento e desengajamento moral apresentados por professores diante do bullying. Para isso, construímos o instrumento, aplicamo-lo, refizemo-lo, testamo-lo, passamos por etapas de julgamento entre pares e, por fim, fomos ajustando os constructos até que seus dados correspondessem à qualidade das informações almejadas.

\section{A amostra}

A amostra total para este estudo é formada de 921 docentes, divididos entre 528 pertencentes à amostra brasileira e 393 à espanhola, compostas por professores de ambos os gêneros. No caso brasileiro, foram envolvidos profissionais de escolas públicas ou privadas de educação básica, situadas em diversos municípios pertencentes ao estado de São Paulo: Paulínia, Campinas, São João da Boa Vista, Santa Bárbara D’Oeste, Araraquara, São Carlos, Nova Odessa, São José do Rio Preto e São Paulo. Há, ainda, docentes em formação, 
estudantes de pedagogia de uma Universidade Federal do Nordeste brasileiro. Quanto à amostra espanhola, os professores participantes desta investigação são docentes de escolas públicas da comunidade autônoma de Castilla y León, atendendo de bebês recém-nascidos a adolescentes de 18 anos, da educação infantil ao bachillerato (preparação opcional para a universidade).

O número de participantes foi estabelecido segundo critério de saturação, que consiste na "suspensão de inclusão de novos participantes quando os dados obtidos passam a apresentar, na avaliação do pesquisador, uma certa redundância ou repetição, não sendo considerado relevante persistir na coleta de dados" (FONTANELLA et al., 2008, p. 17).

\section{Descrição da validação do instrumento}

$\mathrm{O}$ instrumento de coleta de dados foi inspirado em um instrumento anteriormente elaborado por Tognetta e Rosário (2013), com base em estudos prévios sobre a relação entre representações de si e bullying na escola (TOGNETTA; LA TAILLE, 2008; TOGNETTA; BOZZA, 2011; TOGNETTA; VINHA, 2008), além de sustentar-se nos estudos sobre crenças de autoeficácia (ROSÁRIO et al., 2000; ROSÁRIO, 2001).

Levando em consideração que o instrumento inicial era direcionado aos estudantes e, ainda, as especificidades que demarcam o grupo de docentes, optamos pela reformulação do mesmo, a partir da construção de outro que nos permitisse analisar as formas como docentes se engajam ou desengajam em situações envolvendo práticas de bullying na escola. Com isso, embora inspirado em Tognetta e Rosário (2013), o instrumento final sofreu ampla modificação, configurando-se em um novo instrumento de pesquisa. O processo de construção e reformulação será descrito a seguir.

\section{Instrumento Piloto}

Construímos os itens que compõem este instrumento a partir da seleção dos melhores itens para composição do conjunto, primeiramente a partir da Análise Teórica dos Itens (PASQUALI, 2003). Assim, seguindo as recomendações deste autor, nos atentamos para a Análise dos Juízes, que é uma análise realizada por peritos na área do construto, no sentido de certificar se os itens estão se referindo ao que se pretende medir. Segundo Messick (1980), na 
medida em que se verificam evidências baseadas em conteúdo, pondera-se a interpretação para validação de um construto. Por isso, a validade do construto objetiva dar suporte aos significados atribuídos aos escores, caracterizando, assim, um conjunto organizado de evidências que poderão revelar amostras consistentes de resposta. Para isso, contamos com quatro juízes que analisaram todo o processo de formulação e reformulação do instrumento de coleta de dados, os quais analisaram os dados iniciais aplicados em caráter experimental a um número de 62 estudantes de pedagogia, cada uma das respostas e suas frequências.

$\mathrm{Na}$ análise preliminar, identificamos um alto percentual de engajamentos morais e um baixo índice de desengajamentos. Observamos, também, que as questões mais assinaladas se repetiam e que algumas alternativas nunca foram marcadas, sobretudo em formas mais evidentes de desengajamentos morais, consideradas "politicamente incorretas". Desse modo, a análise preliminar evidenciou que dos 62 sujeitos participantes da primeira aplicação, quase $80 \%$ deles (49 docentes) marcaram apenas formas de engajamento moral, demonstrando que os estereótipos de moral e de boas condutas pelos professores estavam facilmente reconhecidos.

Identificado o problema, reformulamos o instrumento sucessivamente, aplicando-o em seguida a mais duas amostragens de igual proporção. Foram três aplicações e reformulações dos dados até que conseguíssemos um instrumento adequado aos participantes e aos objetivos da pesquisa. A construção da quarta versão do instrumento, que deu origem aos dados apresentados neste trabalho, será apresentada a seguir.

\section{Versão final do instrumento}

O instrumento final, após testagem e validação estatística e feita pelos juízes, foi composto pela descrição de duas histórias envolvendo situações hipotéticas de bullying, sendo a História A - HA em torno de um alvo típico de bullying e a História B - HB envolvendo um alvo provocador.

A primeira delas descreve a situação de "Japinha", um alvo típico:

Numa sala de aula há um aluno que todos chamam de "Japinha". Ele tem olhos puxados, é bastante quieto e não participa das conversas entre os outros meninos durante a aula. Todos sabem que sua família voltou do Japão, para onde foi trabalhar e ganhar algum dinheiro. Diariamente, um grupo de três alunos da classe, liderado por Jorge, o faz pagar lanches e refrigerantes para eles. Jorge ameaça Japinha dizendo que, caso se negue a pagar, irá inventar aos seus pais e professores que ele usa drogas. Temendo a reação de seus pais (afinal, são muito rígidos), Japinha paga a conta de 
Jorge e dos colegas. Na classe, mesmo os que não são do grupo de Jorge aproveitam os lanches e refrigerantes, que são divididos entre todos.

Já a segunda história descreve o caso de Paula, uma vítima provocadora:

Paula é uma menina que ninguém quer no grupo. Todas as vezes que alguém começa um assunto, Paula se intromete e parece querer mostrar que sabe mais que todos. As meninas acham que ela é "metida" e se afastam dela. Além disso, quando fala, Paula é tão exagerada que chega, sem querer, a cuspir nas pessoas, o que faz com que os colegas a chamem de nojenta. Os alunos da sala criaram uma página no Facebook com a foto da turma toda segurando um guarda-chuva com a seguinte legenda: "Pode vir, Paula, estamos preparados com o guarda-chuva". Quando soube, Paula agiu como sempre faz - agrediu a todos com tapas e postou comentários ofensivos utilizando-se de palavrões, xingamentos e gestos obscenos.

Ao final de cada história, foram apresentadas 14 alternativas, distribuídas em oito categorias de Desengajamento Moral - DM e seis possibilidades de Engajamento Moral - EM, dispostas de forma randomizada, com o seguinte indicativo: "Para explicar o que acontece nesta situação descrita, assinale as alternativas com que você concorda. Você pode assinalar quantas alternativas quiser".

Em cada história, as seis alternativas indicadoras de EM se dividiram em dois tipos de engajamento delimitados por nós: o primeiro deles, sob a perspectiva da moral pela convenção social, refere-se às respostas em que o conteúdo moral é compreendido pelo sujeito enquanto necessário, mas a explicação dada refere-se a algo que é muito dito ou utilizado socialmente, assumindo a aparência de "politicamente correto". Assim, na história de Japinha as alternativas de EM por convenção social são: “1. Algo deve ser feito, porque o respeito é essencial; 2. Jorge não respeita Japinha. Algo tem que ser feito, já que há uma lei que garante o combate ao bullying; 3. Nos dias de hoje, a intolerância deve ser combatida”. E na história de Paula: "1. É preciso garantir o respeito entre os alunos, afinal, diz o ditado: respeito é bom e eu gosto; 2. Algo deve ser feito, porque esse tipo de comportamento é intolerável; 3. A escola deve conscientizar a todos sobre os valores morais que estão perdidos nessa geração".

A segunda forma de EM corresponde à escolha moral por princípio, ou seja, de modo não condicionado à sua presença ou não nas convenções sociais. Na história de Japinha, as alternativas referentes ao EM por princípio são: “1. Os professores são os principais responsáveis pela solução desse problema; 2. Todos os alunos, mesmo os que agem mal, têm o mesmo direito de ser bem tratados; 3. A escola não deve ignorar que esse é um problema moral”. Já na história de Paula: “1. Falta aos colegas de Paula reconhecer que ela está 
sofrendo; 2. É tarefa da escola a educação moral dos alunos para garantir a convivência respeitosa; 3. Todos os alunos, mesmo Paula, que age mal, têm o mesmo direito de ser bem tratados".

Quanto às alternativas de desengajamento moral, essas foram construídas a partir das categorias descritas por Bandura sobre os desengajamentos e agrupadas por nós nas categorias: Desengajamentos morais que negam o conteúdo moral e desengajamento moral que não negam o conteúdo moral. Dentre as alternativas que não negam o conteúdo moral são elas:

1) Comparação vantajosa: A comparação pode ser outro meio de fazer uma conduta prejudicial parecer boa. A maneira como o comportamento é visto pode perder a gravidade a partir de outra ação com a qual é comparada. O julgamento da gravidade justifica a escolha das opções. No instrumento: HA - "Por enquanto, esta situação ainda é 'tolerável'. Porém, se ela passar do limite, chegando à agressão física, será imprescindível uma intervenção"; e HB - "Paula age de forma desproporcional. Afinal de contas, as outras pessoas não chegaram a agredi-la fisicamente".

2) Difusão da responsabilidade: As pessoas comportar-se-ão de maneira que elas normalmente repudiariam, se uma autoridade legítima aceitar a responsabilidade pelos efeitos das suas condutas. As pessoas veem suas ações como decorrentes das ordens das autoridades, elas não se sentem responsáveis pelos conflitos. No instrumento: HA - "Esses comportamentos são muito comuns nas novelas, filmes e jogos de vídeo game que os alunos jogam"; e HB - "Hoje em dia, a Internet é Terra de ninguém. Lá os alunos aprendem todos os tipos de palavrão e comportamentos obscenos".

3) Deslocamento de Responsabilidade, que consiste em atribuir a outrem a responsabilidade pelo problema, isentando os demais de qualquer obrigação em intervir na superação. No instrumento: HA - "Se os pais de Japinha fossem de conversar e procurar saber do dia a dia do seu filho, talvez isso não acontecesse"; e HB - "Hoje em dia as famílias estão muito desestruturadas. Os pais de Paula não a educaram bem, como deveriam".

4) Minimização ou Distorção das Consequências, que consiste em diminuir ou negar a gravidade do fato, minimizando as suas consequências. No instrumento: HA - "Se os adultos resolverem intervir a cada situação como essa, achando que tudo é bullying, os adolescentes nunca terão a oportunidade de enfrentar os seus próprios problemas, sendo, portanto, frágeis emocionalmente"; e HB - "Se o professor tiver que parar a todo RIAEE - Revista Ibero-Americana de Estudos em Educação, Araraquara, v. 16, n. 1, p. 292-319, jan./mar. 2021. e-ISSN: 1982-5587 DOI: https://doi.org/10.21723/riaee.v16i1.14477 (cc) BY-NC-SA 
momento para resolver conflitos, ele não dará mais aula, prejudicando o andamento dos conteúdos".

As formas de Desengajamento Moral que negam o conteúdo moral são:

1) Justificativa moral: Neste caso, a conduta prejudicial é transformada em pessoal e moralmente aceitável ao retratá-la como sendo socialmente válida ou com propósitos morais. As pessoas podem agir em um imperativo moral e preservarem sua visão de si mesmas como agentes morais enquanto causam danos às outras. No instrumento: HA - "Os meninos não são do mesmo grupo de Japinha. Se fossem amigos, não o tratariam mal"; e HB - "Falta educação à Paula. Por isso a tratam mal".

2) Linguagem eufemística. Refere-se ao tipo de linguagem que é amplamente usada para tornar a conduta danosa respeitável e reduzir a responsabilidade pessoal por ela. Há um mascaramento das atividades repreensivas com o objetivo de diminuir a gravidade da ação. No instrumento: HA - "Isso é uma brincadeira de adolescente, retratada como violência pela mídia sensacionalista que, por influência da televisão, ganhou tons de violência"; e HB - "Isso que acontece com Paula e sua turma é uma brincadeira muito comum entre os alunos nessa idade. Nossa geração também passou por isso".

3) Desumanização. Quando retiram das pessoas suas qualidades humanas ou acrescentam a elas qualidades desumanas. É transmitido à vítima uma impressão de uma pessoa desagradável ou desprezível. No instrumento: HA - “Japinha era muito diferente de todos. Não era normal"; e HB - "Paula não está se comportando como uma pessoa civilizada, mas deveria se comportar. Desse jeito, Paula nem parece gente".

4) Culpabilização da vítima. A vítima é responsabilizada pelo que lhe acontece. A vítima é julgada e culpada por estar sendo alvo de vitimização. No instrumento: HA - “A timidez de Japinha deveria ser trabalhada. Inclusive, é por causa dela que ele acaba se excluindo do grupo". E para HB - "Paula não se esforça para melhorar o relacionamento dela com os colegas. Agindo dessa forma, Paula dá motivos para os colegas a tratarem assim".

Os testes para verificar se o modelo original foi capaz de proporcionar um bom ajuste dos dados foram iniciados após o encerramento das coletas no Brasil. Para isso, valemo-nos da análise fatorial confirmatória ou modelo de equações estruturais para mensurarmos a validade de nosso questionário para a amostra brasileira. Uma vez que o questionário anterior, 
para adolescentes, foi validado utilizando-se da análise fatorial confirmatória, a escolha da mesma conduta foi adotada em relação a esse questionário. De acordo com Urbina (2007), a validade de um instrumento de investigação corresponde a um critério de medida que ratifica sua qualidade para mensurar aquilo que o pesquisador se propõe a medir. A validade, conforme a autora salienta, dependerá de testes estatísticos que eventualmente confirmarão se o instrumento consegue evidenciar as inferências esperadas pelo pesquisador.

Para Pasquali (2001), as exigências para a construção e posterior validação de um instrumento são três: 1. Procedimentos teóricos iniciais pertinentes ao constructo; 2. Coleta empírica de informações; e 3. Análises para validação estatística das informações coletadas. Este rigor metodológico é imprescindível à credibilidade perante a comunidade científica, pois, a fim de que suas implicações possam ser generalizáveis para outros contextos, os dados precisam adquirir confiabilidade.

Partindo da perspectiva do desenvolvimento da moralidade segundo a Epistemologia Genética, sentimos a necessidade de apontar as escolhas dos sujeitos como um processo de desenvolvimento e, portanto, antes da submissão de nosso instrumento de investigação às análises estatísticas voltadas à conferência de sua validade interna e confiabilidade, estabelecemos quatro fatores, ao invés de dois que compunham o instrumento anterior. Com isso, considerando os juízos morais sob a perspectiva de sua evolução, estabelecemos como primeiro fator (F1) as categorias de DM que têm, em comum, a negação do conteúdo moral explicitado. Diante disso, pertencem à $\mathrm{F} 1$ as categorias culpabilização, linguagem eufemística, desumanização e justificativa moral. Como F2, foram elencadas as categorias de DM sem a negação do conteúdo moral, o que caracteriza, a nosso ver, um passo neste desenvolvimento, ainda que como desengajamento. Portanto, neste conjunto se inserem a transferência de responsabilidade, difusão de responsabilidade, minimização ou distorção das consequências e comparação vantajosa.

A apropriação da teoria de Bandura (1999; 2015), a partir de nossa posição epistemológica, leva-nos a considerar uma leitura cujo olhar se dá sobre o desenvolvimento e, logo, da evolução, mesmo que, ao conceber os mecanismos de $\mathrm{DM}$, o próprio autor não tenha estabelecido uma hierarquia entre eles. Nesse sentido, embora ao estabelecermos tal distribuição dos mecanismos em fatores estejamos pressupondo distinções do ponto de vista da natureza de seus conteúdos - F1 nega o conteúdo moral enquanto que F2 não -, tais distinções não necessariamente se estendem à lógica correspondente ao que, à ótica banduriana, explicaria seus efeitos perante a dimensão psíquica dos sujeitos: amenizar ou, até 
mesmo, eliminar as autossanções morais que, sem a utilização dos DMs, lhes seriam impostas em virtude do confronto entre a moral e a omissão diante da falta dela.

Seguindo com a descrição dos fatores estabelecidos, é sob a mesma perspectiva teórica da Epistemologia Genética que, de forma subsequente, estabelecemos os fatores F3 e F4, respectivamente concebidos pelo EM por convenção social e EM por princípio, ambos compostos pelas alternativas indicadoras da adesão aos conteúdos morais ausentes nas histórias apresentadas. Neste caso, a distinção entre F3 e F4 manifesta-se na ordem da própria natureza que subjaz à tendência de adesão ao conteúdo moral sugerido: condicional ou não à sua enunciação através das convenções ou dos dispositivos normativos da sociedade. A Figura 1 sintetiza esse ordenamento. Nela, "HA" refere-se à história A (de Japinha). "HB" se refere à história $\mathrm{B}$ (de Paula). Os números que seguem as letras correspondem às alternativas no instrumento:

Figura 1 - Distribuição das alternativas conforme os Fatores

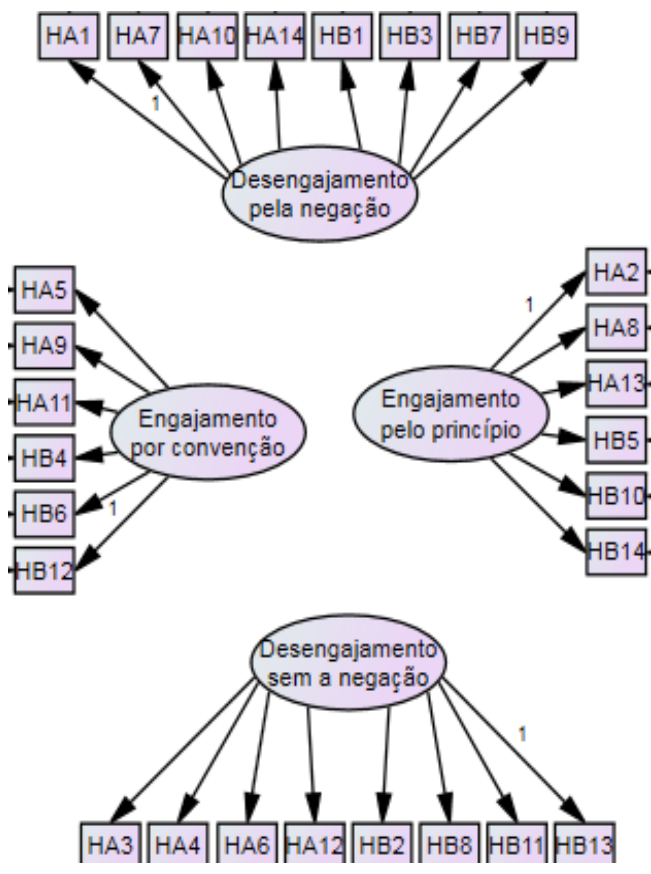

Fonte: Elaborado pelos autores 
Finalmente, com o objetivo de clarificar as relações entre a criação dos fatores e a qualificação dos juízos morais dos sujeitos como a manifestação de uma tendência - termo que descarta a existência de uma pessoa puramente desengajada ou engajada moralmente -, reiteramos que, de acordo com o postulado pela Epistemologia Genética, os sujeitos não se posicionam estaticamente em um determinado ponto do limiar estabelecido entre F1 (o menos evoluído) e F4 (o mais evoluído), mas, pelo contrário, tendem a se movimentar entre eles.

Portanto, é considerando as respostas a partir de seu conjunto - ou seja, não de modo isolado ou pela simples análise da frequência das alternativas -, que se pretende qualificar as respostas dadas pelos sujeitos: além de estipular os fatores que mencionamos, alocamos as respostas obtidas em níveis de 1 a 4 , projetados a partir do limiar representado na figura anterior e mensurados de acordo com as possíveis combinações entre os fatores.

Tais níveis, portanto, foram compostos em ordem crescente de acordo com a qualidade moral correspondente aos fatores combinados. Deste modo, o nível de desenvolvimento um (ND1) engloba apenas as respostas de DM, ou seja, aquelas assinaladas somente em F1 e F2. O nível dois (ND2) corresponde às respostas de sujeitos que assinalaram as duas formas possíveis de DM (F1 e F2) e a forma de EM por convenção (F3). O nível três (ND3) é estipulado de acordo com as respostas dos sujeitos que assinalaram alternativas de F2 e F3 e F4, ou seja, embora apontem para o DM, elas não negam o valor moral. Por fim, o nível quatro (ND4), considerado o mais desenvolvido do ponto de vista da qualidade moral das alternativas assinaladas, corresponde ao grupo de respostas marcadas apenas entre as relacionadas ao $\mathrm{EM}(\mathrm{F} 3$ e F4).

O Quadro 1, a seguir, compõe níveis conforme suas respectivas combinações entre os fatores. Nele, ND corresponde a "nível de desenvolvimento". O número indica, por ordem crescente, o nível da tendência a respostas cada vez mais moralmente evoluídas:

Quadro 1 - Os níveis e seus respectivos fatores combinados

\begin{tabular}{|l|l|}
\hline Níveis & \multicolumn{1}{|c|}{ Fatores } \\
\hline ND1 & F1; F2; F1 e F2 \\
\hline ND2 & F1 e F3; F1 e F4; F2 e F3; F1, F2 e F3; F1, F2 e F4; F1, F3 e F4; F1, F2, F3 e F4 \\
\hline ND3 & F2 e F4; F2, F3 e F4 \\
\hline ND4 & F3; F4; F3 e F4 \\
\hline
\end{tabular}

Fonte: Elaborado pelos autores

Apresentamos os procedimentos e resultados que culminaram em sua validação estatística. O início da validação estatística de nosso instrumento se deu após o 
estabelecimento dos fatores e a partir do modelo original estimado via Mínimos Quadrados Ponderados Robustos (WLSMV), um teste estatístico adequado a este tipo de investigação, cujas variáveis em estudo são categóricas. As informações sobre discrepâncias no modelo de ajuste disponíveis a partir das relações entre os erros foram usadas para fazer as modificações post hoc e, consequentemente, melhorar o ajuste do modelo.

O software utilizado para esta validação foi o MPLUS 6.12. O ajuste do modelo foi obtido a partir de cinco índices de ajuste: $\mathrm{X}^{2}$, WRMR (weighted root mean square residual), CFI (Comparative Fit Index), TLI (Tucker-Lewis Index) e RMSEA (Root Mean Square Error of Aproximation).

$\mathrm{O} \mathrm{X}^{2}$ avalia a qualidade do ajuste do modelo, comparando a matriz de correlação amostral com a de correlação estimada sob o modelo. Menores valores, nesse caso, indicam um bom ajuste, indicando a pequena discrepância entre a estrutura dos dados observados e o modelo hipotético.

Em nosso instrumento, o $\mathrm{X}^{2}$ foi igual a 470,36 (GL 344). Como o $\mathrm{X}^{2}$ é sensível ao tamanho da amostra, índices adicionais devem ser utilizados, já que ele, por si só, não pode ser considerado um teste de ajuste. Por isso, recorremos à análise estatística dos índices CFI e TLI, que compararam o modelo hipotético a um modelo "nulo" - um modelo independente em que as covariâncias entre todas as variáveis são iguais a zero - ou a um de pior ajuste, considerando-se a complexidade do modelo. Tais índices podem variar de 0 a 1 , sendo que os valores próximos a 1 são considerados bem ajustados. Portanto, com base nestes critérios, nosso modelo pode ser considerado bem ajustado, visto que os valores de CFI e TLI foram, respectivamente, 0,843 e 0,827 .

Outro índice que utilizamos durante o processo de validação deste instrumento foi o RMSEA, que estima o quanto os parâmetros do modelo reproduzem a covariância/correlação populacional. Quando um modelo reproduz as covariâncias/correlações populacionais com exatidão, o RMSEA é igual a 0. Para Brown (2006), com base neste índice valores abaixo de 0,06 são indicativos de um ajuste razoável do modelo. No entanto, em alguns casos o modelo com o índice RMSEA de até 0,08 pode ser considerado válido. Em nosso instrumento, o RMSEA foi de 0,33 (IC 95\%: 0,024 - 0, 041), fato que garante ter sido bem parametrizada a população para este estudo.

Finalmente, nosso índice WRMR, que mede a diferença média ponderada entre as covariâncias amostrais e as covariâncias populacionais estimadas, foi de 1,149, razoável diante da sugestão de Yu (2002), na qual se recomenda um ponto de corte igual a 1. Diante da 
constatação de que três dos nossos quatro índices de ajuste foram considerados muito bons, nosso instrumento pode ser considerado como validado positivamente.

Através da matriz de correlação tetracórica residual, pudemos obter a informação específica acerca do quanto cada correlação foi reproduzida pelos parâmetros estimados pelo modelo. É desejável que os resíduos estejam próximos de zero. Em nosso instrumento, vimos que, na maioria dos casos, as correlações residuais não superam 0,1 .

Mesmo assim, foram obtidos dois índices de modificação para nosso modelo. Os índices de modificação mostram o quanto o $\mathrm{X}^{2}$ poderia ser reduzido se fosse incorporada a correlação entre dois ou mais elementos do modelo. Portanto, os índices de modificação sugeridos foram (1) a incorporação da alternativa 14 para a história B (HB14) à alternativa 14 para a mesma história (HB6), numa redução de 10,320 no $\mathrm{X}^{2}$; e (2) o remanejamento da alternativa 6 à história A (HA6) para o Fator F4 (redução de 16,082 no $\mathrm{X}^{2}$ ). Consideram-se válidos somente os índices de modificação para os erros de medida, e não as relações para os coeficientes de regressão, uma vez que foi idealizado um modelo sem cargas fatoriais cruzadas entre os domínios, isto é, não existe relação entre um fator latente e alguma variável indicadora pertencente a outro fator latente. Porém, nenhuma das relações indicadas fizeram sentido, uma vez que não faziam parte de uma mesma variável latente do ponto de vista de sua validade teórica que explicasse tal modificação. Sendo assim, o modelo foi mantido em sua forma original, sem covariância entre os erros, até porque o ganho com um novo modelo não seria suficiente para justificar tal modificação.

Observamos, na Tabela 1, as estimativas que foram padronizadas para nosso modelo.

Tabela 1 - Estimativas padronizadas do modelo

\section{Estimativas padronizadas do modelo}

\begin{tabular}{lccc}
\hline \multicolumn{1}{c}{ Relação } & Estimativa & Erro padrão & Valor-p \\
\hline F1 -> HA1 & 0,591 & 0,069 & 0,000 \\
F1 -> HA7 & 0,709 & 0,083 & 0,000 \\
F1 -> HA10 & 0,290 & 0,099 & 0,003 \\
F1 -> HA14 & 0,472 & 0,095 & 0,000 \\
F1 -> HB1 & 0,637 & 0,083 & 0,000 \\
F1 -> HB3 & 0,513 & 0,094 & 0,000 \\
F1 -> HB7 & 0,741 & 0,062 & 0,000 \\
F1 -> HB9 & 0,693 & 0,061 & 0,000 \\
& & & \\
F2 -> HA3 & 0,543 & 0,081 & 0,000 \\
F2 -> HA4 & 0,426 & 0,107 & 0,000
\end{tabular}




\begin{tabular}{|c|c|c|c|}
\hline F2 -> HA6 & 0,430 & 0,081 & 0,000 \\
\hline $\mathrm{F} 2$-> HA12 & 0,262 & 0,095 & 0,006 \\
\hline $\mathrm{F} 2->\mathrm{HB} 2$ & 0,641 & 0,065 & 0,000 \\
\hline F2 -> HB8 & 0,589 & 0,087 & 0,000 \\
\hline $\mathrm{F} 2->\mathrm{HB} 11$ & 0,587 & 0,076 & 0,000 \\
\hline $\mathrm{F} 2$-> HB13 & 0,566 & 0,077 & 0,000 \\
\hline F3 -> HA5 & 0,606 & 0,095 & 0,000 \\
\hline F3 -> HA9 & 0,670 & 0,078 & 0,000 \\
\hline F3 -> HA11 & 0,710 & 0,068 & 0,000 \\
\hline F3 -> HB4 & 0,569 & 0,077 & 0,000 \\
\hline $\begin{array}{l}\text { F3 -> HB6 } \\
\text { F3 -> }\end{array}$ & 0,456 & 0,077 & 0,000 \\
\hline HB12 & 0,506 & 0,078 & 0,000 \\
\hline F4 -> HA2 & 0,268 & 0,101 & 0,008 \\
\hline F4 -> HA8 & 0,711 & 0,076 & 0,000 \\
\hline F4 -> HA13 & 0,568 & 0,081 & 0,000 \\
\hline F4 -> HB5 & 0,515 & 0,075 & 0,000 \\
\hline F4 -> HB10 & 0,412 & 0,082 & 0,000 \\
\hline F4 -> HB14 & 0,747 & 0,078 & 0,000 \\
\hline $\mathrm{F} 1<->\mathrm{F} 2$ & 0,936 & 0,058 & 0,000 \\
\hline $\mathrm{F} 1<->\mathrm{F} 3$ & 0,498 & 0,083 & 0,000 \\
\hline $\mathrm{F} 1<->\mathrm{F} 4$ & $-0,011$ & 0,088 & 0,897 \\
\hline $\mathrm{F} 2<->\mathrm{F} 3$ & 0,462 & 0,087 & 0,000 \\
\hline $\mathrm{F} 2<->\mathrm{F} 4$ & 0,104 & 0,099 & 0,263 \\
\hline $\mathrm{F} 3<->\mathrm{F} 4$ & 0,534 & 0,081 & 0,000 \\
\hline
\end{tabular}

Fonte: Elaborado pelos autores

Através da Tabela 1, constatamos uma correlação fatorial muito importante entre F1 e F2 (0,936 - quanto mais próximo a 1 , mais proximidade). Neste caso, observa-se que os fatores estão muito próximos, fato previsível diante das próprias sutilezas que caracterizam a relação entre as categorias de DM que compõem F1 e F2, anteriormente detalhada em Figura 1. Porém, o caráter que subjaz aos conteúdos sugeridos em F1 (desengajamento com negação do conteúdo moral em jogo) e F2 (desengajamento sem a negação do conteúdo moral) justifica, conforme a perspectiva do juízo moral pensada em termos de evolução (já explicada), a manutenção da distinção entre os fatores, pois a natureza de tal distinção é importante ao que, com este estudo, pretendemos mensurar.

Finalmente, os testes estatísticos, como vimos, trouxeram resultados bastante favoráveis acerca da confiabilidade da consistência interna do instrumento, apesar da 
proximidade entre F1 e F2. Assim, a manutenção dos quatro fatores não implicaria em uma mudança substancial daquilo que havia sito provado como consistente.

Entretanto, na Tabela 1 também é interessante notar, por exemplo, o quanto F1 está distante de F4 (-0,011) - fatores que indicam, respectivamente, por um lado, respostas de DM que, em termos de desenvolvimento, sequer consideram um conteúdo moral em jogo e, por outro, respostas de maior EM. Tal índice indica uma relação de correspondência entre seu significado psicométrico e os pressupostos teóricos com os quais foram elaborados os fatores. Ao elevarmos ao quadrado as cargas fatoriais padronizadas, obtivemos a proporção de variância na variável que é explicada pelo fator latente, conforme Tabela 2.

Tabela 2 - Proporção de variância na variável que é explicada pelo fator latente

\begin{tabular}{lccc}
\hline $\begin{array}{c}\text { Variável } \\
\text { observada }\end{array}$ & Estimativa* & Erro padrão & Valor-p \\
\hline HA1 & 0,350 & 0,082 & 0,000 \\
HA2 & 0,072 & 0,054 & 0,183 \\
HA3 & 0,295 & 0,089 & 0,001 \\
HA4 & 0,181 & 0,091 & 0,046 \\
HA5 & 0,368 & 0,115 & 0,001 \\
HA6 & 0,185 & 0,069 & 0,008 \\
HA7 & 0,503 & 0,118 & 0,000 \\
HA8 & 0,505 & 0,108 & 0,000 \\
HA9 & 0,449 & 0,105 & 0,000 \\
HA10 & 0,084 & 0,057 & 0,142 \\
HA11 & 0,505 & 0,096 & 0,000 \\
HA12 & 0,069 & 0,050 & 0,169 \\
HA13 & 0,323 & 0,092 & 0,000 \\
HA14 & 0,223 & 0,089 & 0,012 \\
HB1 & 0,405 & 0,106 & 0,000 \\
HB2 & 0,412 & 0,084 & 0,000 \\
HB3 & 0,263 & 0,096 & 0,006 \\
HB4 & 0,324 & 0,087 & 0,000 \\
HB5 & 0,266 & 0,077 & 0,001 \\
HB6 & 0,208 & 0,070 & 0,003 \\
HB7 & 0,549 & 0,092 & 0,000 \\
HB8 & 0,347 & 0,103 & 0,001 \\
& 0,481 & 0,085 & 0,000 \\
HB10 & 0,170 & 0,068 & 0,012 \\
HB11 & 0,089 & 0,000 \\
HB12 & 0,345 & 0,079 & 0,001 \\
HB13 & 0,256 & 0,087 & 0,000 \\
HB14 & 0,321 & 0,117 & \\
\hline
\end{tabular}

Fonte: Elaborado pelos autores 
Ao analisar a Tabela 2, podemos observar que nossas alternativas são bem explicadas pelo fator latente (sempre menos que 1). Isso significa que sua variância é pequena, o que indica boa distribuição das categorias nos 4 fatores criados para ambas as histórias. Portanto, com base em todos os índices, nosso modelo foi considerado validado para a amostra desta pesquisa.

\section{Considerações finais}

Com base nos dados decorrentes de todas as análises para a averiguação de evidências de validade dos instrumentos, foi possível aprimorar a matriz de referência dos mecanismos de Engajamento e Desengajamento Moral de docentes diante do bullying na escola. Depois dos estudos piloto e da aplicação do instrumento numa amostra significativa, concluímos a etapa de validade de construto, compreendendo que os dados coletados a partir deste instrumento podem evidenciar mecanismos de Engajamento e Desengajamento Moral que contribuem para melhor compreensão do fenômeno e construção de políticas e formação docente que permitam a superação da violência na escola, em especial das situações de bullying, com o decisivo apoio da intervenção docente qualificada, para contraporem-se à continuada má gestão das violências em contextos educacionais.

Espera-se, ainda, que os dados coletados a partir deste instrumento possam ser disponibilizados ao uso pelas instituições educacionais, a fim de que sejam criados programas de formação continuada de professores que assegurem reflexões favorecedoras de superação dos Desengajamentos Morais. Docentes ainda compreendem equivocadamente a gênese do bullying na escola, contribuindo, a partir deste equívoco, para que adotem mecanismos autoexonerativos de Desengajamentos Morais que justificam suas omissões diante deste problema. Ora, a adoção de Desengajamentos Morais inibe a manifestação do sentimento de culpa, considerado, numa perspectiva piagetiana, como um sentimento autorregulador.

Vale ressaltar: a compreensão dos mecanismos de Desengajamento Moral nos fornece uma síntese das concepções dos professores e, ainda, uma compreensão de suas formas de julgamento moral, apontando para a inserção do debate em torno da formação moral de educadores e educandos como central no processo formativo docente.

Nesse sentido, o instrumento aqui apresentado nos mostra os retratos dos julgamentos docentes, mas, igualmente, permite compreender a natureza da gênese de seus julgamentos, 
pois, a partir dos resultados, podemos refletir sobre a cultura escolar, sobre a formação dos professores e sobre o desenvolvimento moral dos indivíduos.

Destacamos ser preciso termos validado instrumentos capazes de compreender melhor as formas como docentes interpretam as práticas de bullying na escola, a fim de que a formação de professores, buscando contribuir para superação da violência, oriente-se sobre conhecimento científico vigoroso o suficiente para interferir nas políticas públicas de preparação continuada desses profissionais, cujas práticas são determinantes centrais da continuidade ou da superação do bullying e de outras violências na escola. Por isso, também, esperamos que este instrumento seja utilizado por pesquisadores que desejarem realizar investigações nessa área.

\section{REFERÊNCIAS}

ANDRADE, F. Ser uma lição permanente: psicodinâmica da competência inter-relacional do(a) educador(a) na gestão de conflitos e na prevenção da violência na escola. Orientadora: Maria Eulina Pessoa de Carvalho. 2007. 222 f. Tese (Doutorado em Educação) Universidade Federal da Paraíba, João Pessoa, 2007.

AVILÉS, J. Bullying: guia para educadores. Campinas, SP: Mercado de Letras, 2013.

AVILÉS, J. Bullying: el maltrato entre iguales. Agresores, víctimas y testigos en la esculea. Salamanca: Amarú, 2006.

BANDURA, A. et al. Desengajamento moral: teoria e pesquisa a partir da teoria social cognitiva. Campinas: SP. Mercado de Letras, 2015.

BANDURA, A. Selective moral disengagement in the exercise of moral agency. Journal of Moral Education, v. 31, p. 101-119, 2002.

BANDURA, A. Moral disengagement in the perpetration of inhumanities. Personality and Social Psychology Review, v. 3, p. 193-209, 1999.

BERKOWITZ, L. Aggression: its causes, consequences, and control. Mcgraw-Hill Book Company, 1993.

CRAIG, K. B. D.; LESCHIED, A. Pre-service teachers' knowledge and attitudes regarding school-based bullying. Canadian Journal of Education, v. 34, n. 2, p. 21-33, 2011.

DAUD, R. P. (Des)engajamento moral e atuação docente frente ao bullying escolar. Orientadora: Luciene Regina Paulino Tognetta. 2018. 202 f. Dissertação (Mestrado em Educação Escolar) - Universidade Estadual Paulista, Araraquara, 2018.

DEL BARRIO, C. et al. Maltrato por abuso de poder entre escolares ¿de qué estamos hablando? Revista Pediatría Aten Primaria, v. 7, n. 25, p. 75-100, 2005.

RIAEE - Revista Ibero-Americana de Estudos em Educação, Araraquara, v. 16, n. 1, p. 292-319, jan./mar. 2021. e-ISSN: 1982-5587 DOI: https://doi.org/10.21723/riaee.v16i1.14477 
DÍAZS-AGUADO, M. Da violência escolar à cooperação na sala de aula. Americana, SP: Editora Adonis, 2015.

DODGE, K. A. The structure and function of reactive and proactive aggression. In:

Earlscourt Symposium on Childhood Aggression. Toronto, ON, Canada: Lawrence Erlbaum Associates, Inc, 1991.

DODGE, K. A.; COIE, J. D. Social-information-processing factors in reactive and proactive aggression in children's peer groups. Journal of personality and social psychology, v. 53, n. 6, p. 1146, 1987.

FANTÁSTICO. Em nova carta, atirador tenta usar bullying para justificar crime. O Fantástico teve acesso às imagens feitas pela polícia na casa de Wellington na quinta-feira da tragédia. Em meio a muita sujeira, os policiais encontraram uma segunda carta deixada pelo assassino. Rede Globo, Rio de Janeiro, 2011. Disponível em: http://fantastico.globo.com/Jornalismo/FANT/0,,MUL1658408-15605,00$\mathrm{EM}+\mathrm{NOVA}+\mathrm{CARTA}+\mathrm{ATIRADOR}+\mathrm{TENTA}+\mathrm{USAR}+\mathrm{BULLYING}+\mathrm{PARA}+\mathrm{JUSTIFICAR}+$ MASSACRE.html. Acesso em: 7 abr. 2019.

FISCHER, R. M. (Coord.). Bullying escolar no Brasil. Relatório Final. São Paulo: CEATS/FIA, 2010.

FONTANELLA, B. et al. Amostragem por saturação em pesquisas qualitativas em saúde: contribuições teóricas. Caderno de Saúde Pública, Rio de Janeiro, v. 24, n. 1, p. 17-27, jan. 2008. DOI: https://doi.org/10.1590/S0102-311X2008000100003

FRICK, L. Estratégias de prevenção e contenção do bullying nas escolas: as propostas governamentais e de pesquisa no Brasil e na Espanha. Orientadora: Maria Suzana de Stefano Menin. 2016. 272 f. Tese (Doutorado em Educação) - Universidade Estadual Paulista, Presidente Prudente, 2016.

FRICK, L. As relações entre os conflitos interpessoais e o bullying: um estudo nos anos iniciais do Ensino Fundamental de duas escolas públicas. Orientadora: Luciene Regina Paulino Tognetta. 2011. 195 f. Dissertação (Mestrado) - Universidade Estadual Paulista, Presidente Prudente, 2011,

GONÇALVES, C.; ANDRADE, F.; GONZAGA, K. Manejo do Bullying na Escola: responsabilizando os espectadores com a pedagogia institucional. In: GONCALVES, C.; ANDRADE, F. Bullying e violências na escola: análise e prevenção. Curitiba, PR: CRV Editora, 2015. p. 113-136.

GONÇALVES, C. Engajamento e Desengajamento Moral de Docentes diante de situações de bullying envolvendo alvos típicos e provocadores de bullying na escola. Orientadora: Luciene Regina Paulino Tognetta. 2017. 262 f. Tese (Doutorado em Educação) Universidade Federal da Paraíba, João Pessoa, 2017. 
GONÇALVES, C. Concepção e julgamento moral de docentes sobre bullying na escola. Orientador: Fernando Cézar Bezerra de Andrade. 2011. 146 f. Dissertação (Mestrado em Educação) - Universidade Federal da Paraí-ba, João Pessoa, 2011.

GUIMARÃES, L. A. M. et al. "Mobbing" (assédio psicológico) no trabalho: uma síndrome psicossocial multidimensional. Psic.: Teor. e Pesq., Brasília, v. 22, n. 2, maio/ago. 2006. DOI: https://doi.org/10.1590/S0102-37722006000200008

JAMES, A. School bullying. Research briefing, v. 26, p. 21, 2010. Disponível em: https://iamnotscared.pixelonline.org/data/database/publications/384_NSPCC\%20Briefing.pdf. Acesso em: 10 mar. 2019.

LAGERSPETZ, K. M, et al. Group aggression among school children in three schools. Scandinavian Journal of Psychology, v. 23, n. 1, p. 45-52, set. 1982. DOI: https://doi.org/10.1111/j.1467-9450.1982.tb00412.x

LAPA, L. Valentes contra o bullying: a implantação das Equipes de Ajuda, uma experiência brasileira. Orientadora: Luciene Regina Paulino Tognetta. 2019. 330f. Dissertação (Mestrado em Educação Escolar) - Universidade Estadual Paulista, Araraquara, 2019.

LOBATO, V. Concepções de professores sobre questões relacionadas à violência na escola. In: REUNIÃO ANUAL DA ANPED, 29., 2006, Caxambu. Anais [...]. Caxambu, MG: ANPEd, 2006.

MASCARENHAS, S. Bullying e moralidade escolar: um estudo com estudantes do Brasil (Amazônia) e da Espanha (Valladolid). In: CONGRESSO DE PESQUISAS EM PSICOLOGIA E EDUCAÇÃO MORAL (COPPEM), 1., 2009, Campinas. Anais [...]. Campinas, SP: UNICAMP, 2009.

MASCARENHAS, S. Gestão do Bullying e da Indisciplina e Qualidade do Bem-Estar Psicossocial de Docentes e Discentes do Brasil (Rondônia). Psic., Saúde \& Doenças [online], Lisboa, v. 7, n. 1, p. 95-107, 2006.

NASCIMENTO, A. Intimidações na adolescência: expressões da violência entre pares na cultura escolar. Orientadora: Jaileila de Araújo Santos. 2009. 203 f. Dissertação (Mestrado em Psicologia) - Universidade Federal de Pernambuco, Recife, 2009.

OLWEUS, D. Europe - Scandinava - Sweden. In: SMITH, P. K.; MORITA, Y.; JUNGERTAS, J.; OLWEUS, D.; CATALANO, R.; SLEE, P. (Eds.). The nature of school. Bullying A cross-national perspective. London and New York: Routledge, 1999. p. 7-27.

OLWEUS, D. Bullying at School: what we know and what we can do. Cambridge: Blackwell, 1993.

OLWEUS, D. Bullying among school-boys. Children and violence. 1973.

OLWEUS, D. Aggression in the schools: bullies and whipping boys. Hemisphere, 1978. 
OLWEUS, D. Continuity in aggressive and withdrawn, inhibited behavior patterns.

Psychiatry and Social Science, v. 1, p. 141-159, 1981.

OLWEUS, D.; ROLAND, E. 'Mobbing Bakgrunn og tiltak'. Kirke-og under visnings departementet. Oslo, 1983.

PASQUALI, L. Testes Referentes a Constructo: teoria e modelo de construção. In:

PASQUALI, L. et al. Psicometria: teoria dos testes na psicologia e na educação. Petrópolis: Vozes, 2003

PIAGET, J. Para onde vai a educação? Rio de Janeiro: José Olímpio, 2007.

PIAGET, J. O juízo moral na criança. 3. ed. São Paulo: Summus, 1994.

RIBEIRO, E.; GONÇALVES, C.; SANTOS, S. Desengajamento Moral de Docentes: o que nos diz a omissão de professoras diante dos conflitos entre pares? In: ENCONTRO DE PESQUISA EDUCACIONAL DO NORDESTE - REUNIÃO CIENTÍFICA REGIONAL DA ANPED, 24., 2018, João Pessoa. Anais [...]. João Pessoa, PB: UFPB, 2018.

RIGBY, K.; BAGSHAW, D. Prospects of adolescent students collaborating with teachers in addressing issues of bullying and conflict in schools. Educational Psychology, v. 23, n. 5, p. 535-546, 2003.

SAMPIERI, R. H. et al. Metodología de la investigación. México: McGraw-Hill, 2010.

SAMPIERI, R. H.; COLLADO, C. F.; LUCIO, M. P. B. Metodologia de pesquisa. 5. ed. Porto Alegre: Penso, 2013.

SÁNCHEZ, V.; ORTEGA, R. El estudio científico del fenómeno bullying. In: RUIZ, R. O. (Coord.). Agresividad injustificada, bullying y violencia escolar. Alianza Editorial, 2010. p. $55-80$.

TOGNETTA, L. R. P. Construindo a Autonomia Moral na Escola: os conflitos interpessoais e a aprendizagem dos valores. Revista Diálogo Educacional, Curitiba, v. 9, n. 28, p. 525-540, set./dez. 2009. DOI: http://dx.doi.org/10.7213/rde.v9i28.3316

TOGNETTA, L. R. P.; LEME, M. VICENTIN, V. Quando os conflitos nos pertencem. Campinas, SP: Mercado de Letras, 2013.

TOGNETTA, L. R. P.; BOZZA, T. Cyberbullying: quando a violência é virtual - Um estudo sobre a incidência e sua relação com as representações de si em adolescentes. In: GUIMARAES, Á; PACHECO, Z. Caderno de resumos do I Seminário Violar: problematizando juventudes na contemporaneidade. Campinas, SP: FE/UNICAMP, 2010.

TOGNETTA, L. R. P.; LA TAILLE, Y. A Formação de Personalidades Éticas:

Representações de Si e Moral. Psicologia: Teoria e Pesquisa, v. 24 n. 2, p. 181-188, 2008. DOI: https://doi.org/10.1590/S0102-37722008000200007 
TOGNETTA, L. R. P.; VINHA, T. Bullying e intervenção no Brasil: um problema ainda sem solução. In: CONGRESSO NACIONAL DE PSICOLOGIA DA SAÚDE: SAÚDE, SEXUALIDADE E GÊNERO, 8., 2010, Lisboa. Anais [...]. Lisboa, Portugal: ISPA Instituto Universitário, 2010.

TOGNETTA, L. R. P.; VINHA, T. Estamos em conflito: Eu, comigo e com você! Um estudo sobre o Bullying e suas causas afetivas. In: CUNHA, J.; DANI, L. (Org.). Escola, conflito e violências. Santa Maria: Editora da UFSM, 2008. p. 199-246.

YOON, J. et al. How south korean teachers handle an incident of school bullying. School Psychology International, v. 32, n. 3, p. 312-329, 2011.

YU, C. Evaluating cutoff criteria of model fit indices for latent variable models with binary and continuous outcomes. Tese (Doutorado) - University of California Los Angeles, 2002.

\section{Como referenciar este artigo}

TOGNETTA, L. R. P.; MARTÍNEZ, J. M. A.; GONÇALVES, C. C.; ANDRADE, F.; BONI, L. G.; SANTOS, N. C. P. Validação de instrumento sobre engajamento e desengajamento moral de docentes diante do bullying na escola. Revista Ibero-Americana de Estudos em Educação, Araraquara, v. 16, n. 1, p. 292-319, jan./mar. 2021. e-ISSN: 1982-5587. DOI: https://doi.org/10.21723/riaee.v16i1.14477

Submetido em: 30/11/2019

Revisões requeridas: 08/04/2020

Aprovado em: 28/09/2020

Publicado em: 02/01/2021 